\title{
Effectiveness of a Meditation-Based Stress Reduction Program in the Treatment of Anxiety Disorders
}

\author{
Jon Kabat-Zinn, Ph.D., Ann O. Massion, M.D., Jean Kristeller, Ph.D., \\ Linda Gay Peterson, M.D., Kenneth E. Fletcher, Ph.D., Lori Pbert, Ph.D., \\ William R. Lenderking, Ph.D., and Saki F. Santorelli, Ed.D.
}

\begin{abstract}
Objective: This study was designed to determine the effectiveness of a group stress reduction program based on mindfulness meditation for patients with anxiety disorders. Method: The 22 study participants were screened with a structured clinical interview and found to meet the DSM-III-R criteria for generalized anxiety disorder or panic disorder with or without agoraphobia. Assessments, including self-ratings and therapists' ratings, were obtained weekly before and during the meditation-based stress reduction and relaxation program and monthly during the 3-month follow-up period. Results: Repeated measures analyses of variance documented significant reductions in anxiety and depression scores after treatment for 20 of the subjects-changes that were maintained at follow-up. The number of subjects experiencing panic symptoms was also substantially reduced. A comparison of the study subjects with a group of nonstudy participants in the program who met the initial screening criteria for entry into the study showed that both groups achieved similiar reductions in anxiety scores on the $S C L-90-R$ and on the Medical Symptom Checklist, suggesting generalizability of the study findings. Conclusions: A group mindfulness meditation training program can effectively reduce symptoms of anxiety and panic and can belp maintain these reductions in patients with generalized anxiety disorder, panic disorder, or panic disorder with agoraphobia.
\end{abstract}

(Am J Psychiatry 1992; 149:936-943)

$\mathrm{S}$ elf-regulatory behavioral strategies, used alone or as adjuncts to other behavioral or medication regimens, may offer a unique approach to treating anxiety disorders. Three major self-regulatory strategiesmeditation, relaxation, and biofeedback - are currently used in clinical practice for the treatment of anxiety. Research suggests that all three play a role in reducing both physiological and psychological components of

Presented at the annual meeting of the Society of Behavioral Medicine, Chicago, April 18-21, 1990, and at the First International Congress on Behavioral Medicine, Uppsala, Sweden, June 27-July 1, 1990. Received Oct. 18, 1990; revision received Oct. 16, 1991; accepted Dec. 2, 1991. From the Stress Reduction and Relaxation Program, Division of Preventive and Behavioral Medicine, Department of Medicine, and the Department of Psychiatry, University of Massachusetts Medical School. Address reprint requests to Dr. Kabat-Zinn, Stress Reduction and Relaxation Program, Department of Medicine, University of Massachusetts Medical School, 55 Lake Avenue North, Worcester, MA 01605.

Supported by a biomedical research support grant from the University of Massachusetts Medical School.

The authors thank Julianne Miller, M.D., for assistance with diagnostic assessments, Craig Edelbrock, Ph.D., for research design consultation, and William Smith, Anthony Bell, and Kim Trettel for data collection and management.

Copyright ㅇ 1992 American Psychiatric Association.

anxiety in normal populations and that the latter two techniques are effective in anxious populations, although with variable efficacy $(1-6)$.

The research on meditation techniques has been largely limited to nonpsychiatric populations (7). To our knowledge, there are no studies of the effectiveness of meditation for patients with anxiety disorders as delineated by DSM-III or DSM-III-R criteria (8). Two controlled studies $(9,10)$ used meditation for patients with anxiety neurosis as defined by DSM-II criteria, but both lacked standardized diagnostic procedures. There was one uncontrolled study of patients diagnosed as having anxiety neurosis (11). None of these studies used a structured clinical interview for diagnosis. All of them investigated variants of one particular type of meditation, namely, transcendental meditation, in which the practitioner focuses on a mantra-a word or phrase repeated silently to achieve a meditative state.

In general, these studies suggested that transcendental meditation may be as effective as other behavioral techniques, such as biofeedback or relaxation, in the treatment of anxiety. Another uncontrolled study (12) investigated mindfulness meditation as an adjunct to psychotherapy for patients with a wide range of psychiatric disorders, excluding schizophrenia and other psy- 
choses. In that study, Kutz et al. found that according to both the patients' self-assessments and the therapists' assessments, there was moderate to marked improvement in a variety of psychological symptoms, including anxiety, from before to after treatment.

The lack of diagnostic assessment according to standardized diagnostic criteria in previous studies and the widespread practice of studying nonclinical populations (e.g., college students) limit the applicability of research findings regarding the clinical effectiveness of meditation. Moreover, the majority of the studies of the effects of meditation on anxiety have relied solely on measures of state-trait anxiety to determine outcome. Such measures do not adequately assess the presence of panic attacks or avoidance behavior and may fail to capture the complexity of clinically significant anxiety symptoms.

The present pilot study was devised to address some of the shortcomings of previous research that investigated the relation between meditation training and anxiety reduction. The study was conducted in conjunction with a well-established outpatient program for stress reduction and relaxation that involves intensive training in mindfulness meditation $(13,14)$, with emphasis on its practical applications in coping with stress and in enhancing adaptive health behaviors. Like other forms of meditation such as transcendental meditation, mindfulness meditation helps practitioners to cultivate greater concentration and relaxation (15). It differs specifically from transcendental meditation by training practitioners to attend to a wide range of changing objects of attention while maintaining moment-to-moment awareness (mindfulness), rather than restricting one's focus to a single object such as a mantra (16) (see the Method section for an operational definition). The choice of mindfulness as the primary meditative approach was due to its immediate applicability to a great variety of present-moment experiences. This orientation lends a quality of "ordinariness" to the intervention that makes it more acceptable and accessible to a wide range of people with different life stressors and different medical disorders (17).

The stress reduction and relaxation program serves a broad spectrum of patients with both physical and psychological disturbances (18). Previous studies have shown that participation in the program results in reductions in both physical and psychological symptoms of patients in many diagnostic categories. Chronic pain patients participating in the program reported markedly reduced levels of state anxiety (as measured with the Symptom Checklist-90-Revised) during the intervention period-levels that were maintained over a 4year follow-up period $(17,19,20)$. Similar changes were reported over a 2-year follow-up period by patients with stress-related medical disorders (Kabat-Zinn, unpublished manuscript).

The specific objectives of the present investigation were 1) to conduct a prospective outcome study, with a repeated measures design, to test the efficacy of treating patients diagnosed with anxiety disorders according to
$D S M-I I I-R$ criteria in a well-established, meditationbased outpatient stress reduction program and 2) to examine whether variables at intake were predictive of outcome at follow-up.

\section{METHOD}

Potential subjects were selected from among all patients referred to the stress reduction and relaxation program in two consecutive cycles (spring and fall of 1988). The Symptom Checklist-90-Revised (SCL-90-R) (21) and the Medical Symptom Checklist (17) were administered to all patients referred to the program, as part of the intake evaluation. Those who scored above the 70th percentile on the anxiety subscale of the SCL90-R and reported more than 10 anxiety-related symptoms (out of 37 possible symptoms) on the Medical Symptom Checklist were invited to take part in a formal screening interview to assess their appropriateness for inclusion in the study. A referral diagnosis of panic attacks or anxiety also qualified an individual to be invited to participate in the screening procedure for the study. Patients who met the study criteria and who agreed to participate were then interviewed by either a psychologist or a psychiatrist trained in administering the Structured Clinical Interview for DSM-III-R (SCID) (22). Diagnoses were determined after review of the SCID data by the two psychologists (J.K. and L.P.) and two psychiatrists (A.O.M. and L.G.P.) who conducted the individual screening evaluations. Only the patients who met the formal diagnostic criteria for generalized anxiety disorder or panic disorder with or without agoraphobia were included in the study. Individuals were excluded if they had other primary psychiatric diagnoses, any disorder with psychotic symptoms, any endocrine disorder, or significant current alcohol or substance abuse. Because of the small sample size and the pilot nature of the study, patients taking anxiolytic or other medications $(\mathrm{N}=12)$ were not excluded. Medication type and usage were assessed for all patients during the study.

In the two cycles of the program from which patients were recruited for this study, $192(60 \%)$ of 321 patients satisfied the initial screening criteria of the SCL-90-R and the Medical Symptom Checklist. However, for logistical reasons and because this was a pilot study, only 44 patients were invited to undergo further screening, of whom 32 completed the evaluation. Of these, $24 \mathrm{met}$ the DSM-III-R criteria for generalized anxiety disorder or panic disorder with or without agoraphobia according to the SCID. Of the eight excluded patients, four had other primary psychiatric diagnoses and four had no psychiatric disorder. Two of the 24 subjects did not complete the program and were not included in the analysis of outcome. Both of these individuals had psychiatric diagnoses of generalized anxiety disorder.

Because of the exploratory nature of the study, we used a repeated measures design with patients serving as their own controls on multiple pretreatment and post- 
treatment measures. In addition, study participants were compared on the SCL-90-R and Medical Symptom Checklist with other patients who met the initial screening criteria and were enrolled in the stress reduction and relaxation program during the same time period but who were not invited to take part in the study. This second group of patients (termed "nonstudy participants") received the same meditation intervention but did not undergo screening or the weekly assessments that the study subjects underwent.

Subjects who met the diagnostic criteria and agreed to participate in the study were evaluated with both self-rating scales and ratings of trained interviewers. Data on the following measures were gathered by telephone interview at weekly intervals from the time of recruitment through the end of treatment and at monthly intervals for 3 months after treatment: the Beck Anxiety Inventory (used by special permission of Jeffrey Sugerman, Ph.D., Psychological Corp., personal communication), the Beck Depression Inventory (23), and ratings of the frequency and severity of panic attacks. The length of time between recruitment and the start of treatment in which data were collected varied according to when subjects were recruited into the study relative to the beginning of the program (range=1-8 weeks).

In addition to these assessments, a more extensive assessment battery was administered four times: at recruitment into the study, at the start of the program (pretreatment), at completion of the program (posttreatment), and at 3-month follow-up. This battery consisted of the Hamilton Rating Scale for Anxiety (24) (as modified by DiNardo and Barlow [25] to include a separate rating scale for symptoms present during panic attacks, yielding the Hamilton panic score), the Hamilton Rating Scale for Depression (26), the Fear Survey Schedule (27), and the Mobility Inventory for Agoraphobia (28). At recruitment patients were also asked to rate on a 5-point scale their expectancy of improvement due to the treatment. A compliance questionnaire was administered at the end of treatment and at follow-up. Eight subjects entered the study so close to the beginning of the treatment intervention that only pretreatment, posttreatment, and follow-up measures were obtained.

The Hamilton anxiety and depression rating scales were administered at recruitment by the same clinicians who administered the SCID. Subsequent Hamilton assessments were administered to all subjects by one trained interviewer. To minimize bias in data collection related to expectancy of change, scoring was done after all data were collected.

The stress reduction and relaxation program is a highly structured training program in mindfulness meditation and its applications, described in detail elsewhere $(14,17-20)$. It takes the form of an 8-week-long course in which participants attend weekly 2-hour classes and, in addition, a 7.5-hour intensive and mostly silent "meditation retreat" session in the sixth week. During each 8-week cycle, five separate but par- allel classes are offered. Each is led by one instructor who stays with that group for the duration of the course. Each class has approximately 30 participants with a wide range of medical and psychological disorders. During classes and for homework, participants practice a range of different formal and informal meditation techniques $(14,17)$. These experiences are discussed weekly in the classes. The 22 subjects in this study were distributed among five of the 10 classes held during that period. The exposure of these subjects differed from that of the remainder of the program participants only in their involvement in the additional assessment protocol required for the study. Four program instructors conducted classes in this study. The instructors did not know which patients were in the study, nor did they know the patients' DSM-III-R diagnoses.

We used repeated measures analysis of variance (ANOVA) to compare the recruitment, pretreatment, posttreatment, and 3-month follow-up scores of the subjects for whom all data points were available, with computation of appropriate contrasts. Matched $t$ tests were used to calculate intervention effects between the pretreatment and posttreatment assessments for the entire sample. Intergroup comparisons of compliance and expectancy measures were done with standard $t$ tests. Variables expected to predict outcome were studied with ANOVA. We plotted the weekly scores of all subjects to examine the course of change, but formal single-subject analyses are not included in this report because of the consistency and strength of the group effects. In addition, after accounting for pretreatment scores with the regression technique described by Cohen and Cohen (29), we compared posttreatment scores of the subjects receiving medication with those of the subjects taking no medication. Finally, we used $t$ tests to compare the study participants and nonstudy participants in the program on pretreatment and posttreatment SCL-90-R scores, Medical Symptom Checklist scores, and change scores.

\section{RESULTS}

Of the 22 study participants who completed the program, 10 had panic disorder with agoraphobia, four had panic disorder without agoraphobia, and eight had generalized anxiety disorder as the primary psychiatric diagnosis. Seventeen subjects had more than one psychiatric diagnosis; 14 had other anxiety disorders and eight had diagnoses of major depressive episode (six concurrent). The average duration of their anxiety disorders was 6.5 years (range $=3$ months to 28 years). Eleven patients were taking medication for their anxiety disorders at intake, and 11 were taking no medication for anxiety.

The subjects' ages ranged from 26 to 64 years, with an average of 38 years. There were five men and 17 women. Eighteen of the subjects were married, two were single, and one was separated (data on one subject were missing).

The recruitment and pretreatment scores on the Ham- 
KABAT-ZINN, MASSION, KRISTELLER, ET AL.

TABLE 1. Scores on Outcome Measures Over Time of Patients With Anxiety Disonders in a Study of a Meditation-Based Stress Reduction Program

\begin{tabular}{|c|c|c|c|c|c|c|c|c|c|c|c|c|}
\hline \multirow[b]{2}{*}{ Measure } & \multirow[b]{2}{*}{$\mathbf{N}$} & \multicolumn{2}{|c|}{$\begin{array}{c}\text { Initial } \\
\text { Recruitment }\end{array}$} & \multicolumn{2}{|c|}{ Pretreatment } & \multicolumn{2}{|c|}{ Posttreatment } & \multicolumn{2}{|c|}{$\begin{array}{l}\text { 3-Month } \\
\text { Follow-Up }\end{array}$} & \multicolumn{3}{|c|}{$\begin{array}{c}\text { Repeated Measures } \\
\text { ANOVA }\end{array}$} \\
\hline & & Mean & SD & Mean & SD & Mean & SD & Mean & SD & $\mathbf{F}$ & df & $\mathbf{p}$ \\
\hline $\begin{array}{l}\text { Hamilton Rating Scale for Anxiety } \\
\text { Hamilton Rating Scale for Depression } \\
\text { Beck Anxiety Inventory } \\
\text { Beck Depression Inventory } \\
\text { Fear Survey Schedule } \\
\text { Mobility Inventory for Agoraphobia }\end{array}$ & $\begin{array}{l}14 \\
14 \\
15 \\
15 \\
11\end{array}$ & $\begin{array}{r}30.36 \\
33.07 \\
24.13 \\
18.87 \\
118.73\end{array}$ & $\begin{array}{r}8.53 \\
7.98 \\
13.49 \\
10.37 \\
41.31\end{array}$ & $\begin{array}{l}26.93 \\
31.07 \\
20.53 \\
16.47 \\
93.55\end{array}$ & $\begin{array}{r}11.13 \\
8.43 \\
13.24 \\
10.97 \\
34.09\end{array}$ & $\begin{array}{r}17.86 \\
23.71 \\
9.00 \\
10.00 \\
78.46\end{array}$ & $\begin{array}{r}9.18 \\
5.59 \\
9.14 \\
9.58 \\
44.28\end{array}$ & $\begin{array}{r}15.86 \\
25.14 \\
7.93 \\
7.53 \\
66.82\end{array}$ & $\begin{array}{r}8.65 \\
7.01 \\
7.29 \\
8.77 \\
38.68\end{array}$ & $\begin{array}{r}21.1 \\
8.87 \\
15.36 \\
9.96 \\
9.79\end{array}$ & $\begin{array}{l}3,39 \\
3,39 \\
3,42 \\
3,42 \\
3,30\end{array}$ & $\begin{array}{l}<0.001^{a} \\
<0.001^{a} \\
<0.001^{a} \\
<0.001^{a, b} \\
<0.001^{c, d}\end{array}$ \\
\hline $\begin{array}{l}\text { Accompanied } \\
\text { Unaccompanied }\end{array}$ & $\begin{array}{l}10 \\
10\end{array}$ & $\begin{array}{l}45.80 \\
61.80\end{array}$ & $\begin{array}{l}16.22 \\
24.40\end{array}$ & $\begin{array}{l}41.30 \\
53.50\end{array}$ & $\begin{array}{l}16.81 \\
24.09\end{array}$ & $\begin{array}{l}36.40 \\
45.50\end{array}$ & $\begin{array}{l}12.02 \\
17.19\end{array}$ & $\begin{array}{l}36.70 \\
46.20\end{array}$ & $\begin{array}{l}13.52 \\
18.87\end{array}$ & $\begin{array}{l}4.05 \\
6.62\end{array}$ & $\begin{array}{l}3,27 \\
3,27\end{array}$ & $\begin{array}{l}<0.05^{e} \\
<0.01^{\text {cee }}\end{array}$ \\
\hline
\end{tabular}

asignificant change from pretreatment to posttreatment $(p<0.01)$.

Trend for significant change from posttreatment to follow-up ( $p<0.10)$.

'Significant change from recruitment to pretreatment $(p<0.05)$.

dSignificant change from posttreatment to follow-up ( $p<0.05)$.

Trend for significant change from pretreatment to posttreatment $(p<0.10)$.

ilton Rating Scale for Anxiety, the Hamilton Rating Scale for Depression, the Beck Anxiety Inventory, the Beck Depression Inventory, the Fear Survey Schedule, and the Mobility Inventory for Agoraphobia of the subjects with complete data at the four primary assessment points are shown in table 1 . They were in the moderate to severe range on both the Beck and the Hamilton anxiety scales and in the mild to moderate range on the Beck and Hamilton depression scales.

At recruitment, nine individuals reported one or more panic attacks in the previous week (range $=1-3$ ), with a mean Hamilton panic score of 26.11 ( $S D=11.25$, range $=6-40$ ). At pretreatment assessment, 13 individuals reported at least one panic attack in the previous week (range $=1-2$ ), with a mean Hamilton panic score of $24.46(\mathrm{SD}=8.71$, range $=11-34)$. At pretreatment the mean SCL-90-R general severity index score of the 22 subjects was $1.10(\mathrm{SD}=0.70$, range $=0-3)$ and the mean SCL-90-R anxiety score was 1.61 ( $S D=1.05$, range $=0-3$ ).

Repeated measures ANOVA indicated that among subjects for whom scores at all four primary assessment points were available, the Hamilton and Beck anxiety and depression scale scores showed small, statistically nonsignificant reductions from baseline to pretreatment, highly significant decreases over the course of the intervention (pretreatment to posttreatment), and maintenance of these changes from posttreatment to follow-up (table 1). Comparisons with matched t tests at pretreatment and posttreatment time points for all subjects, not just those with complete data at all time points, showed comparable results, with mean pretreatment and posttreatment scores, respectively, of 25.86 $(\mathrm{SD}=10.56)$ and $17.10(\mathrm{SD}=9.31)$ on the Hamilton anxiety scale $(t=5.18, d f=20, p<0.001)$ and $30.85(S D=$ 8.81) and 23.85 ( $S D=6.65)$ on the Hamilton depression scale $(t=4.88, d f=19, p<0.001)$. Mean pretreatment and posttreatment scores, respectively, were 20.32 ( $\mathrm{SD}=$ $12.05)$ and $7.09(S D=8.20)$ on the Beck Anxiety Inventory $(t=6.14, d f=21, p<0.001)$ and $16.18(S D=10.33)$ and $8.18(\mathrm{SD}=8.53)$ on the Beck Depression Inventory $(t=4.65, \mathrm{df}=21, \mathrm{p}<0.001)$. These represented mean reductions of $34 \%, 23 \%, 65 \%$, and $49 \%$, respectively, on the four scales. Twenty of the 22 subjects showed marked improvement in scores on the Beck and Hamilton anxiety and depression scales.

The means of the subjects' weekly ratings of anxiety and depression on the respective Beck scales are presented in figures 1 and 2. These show elevated levels before treatment, a significant decline during treatment to a relatively low level by the end of treatment, and maintenance of the lower posttreatment level over 3 months of follow-up. Scores for "accompanied" on the Mobility Inventory for Agoraphobia showed a similar pattern of improvement. However, scores for "unaccompanied" on that inventory and scores on the Fear Survey Schedule improved as much from recruitment to pretreatment assessment as from pretreatment to posttreatment assessment (table 1).

Of the 13 patients who reported at least one panic attack in the preceding week at pretreatment assessment, five reported one panic attack in the previous week at posttreatment assessment (mean Hamilton panic score $=22.0, S D=8.40$, range $=13-34$ ). At 3-month follow-up, three of the original 13 patients reported one attack in the previous week (mean Hamilton panic score $=18.0, \mathrm{SD}=6.24$, range $=11-23$ ). This was a statistically significant decrease in the number of individuals reporting panic attacks from pretreatment to posttreatment to follow-up assessment (Cochran's $Q=14.60$, $\mathrm{df}=2, \mathrm{p}<0.001, \mathrm{~N}=20$ ). Within this group, the individuals whose primary psychiatric diagnosis was panic disorder with or without agoraphobia also showed a statistically significant linear decrease from pretreatment to posttreatment to follow-up (Cochran's $Q=12.67, \mathrm{df}=2$, $\mathrm{p}<0.005, \mathrm{~N}=13$ ).

In both groups there was a significant decline in Hamilton panic scores between pretreatment and posttreatment assessments. For the subjects who reported at least one panic attack at pretreatment assessment $(\mathrm{N}=13)$, the mean pretreatment Hamilton panic score was $24.46(\mathrm{SD}=8.71)$ and the mean posttreatment Hamilton panic score was $8.46(\mathrm{SD}=12.15)(\mathrm{t}=4.75$, $\mathrm{df}=12, \mathrm{p}<0.001)$. For the panic disorder subset $(\mathrm{N}=11)$, the mean pretreatment Hamilton panic score was 24.64 
FIGURE 1. Mean Beck Anxiety Imwentory Ratinges Before, During, and After Treatment of Patients in a Meditation-Based Stress Reduction Program

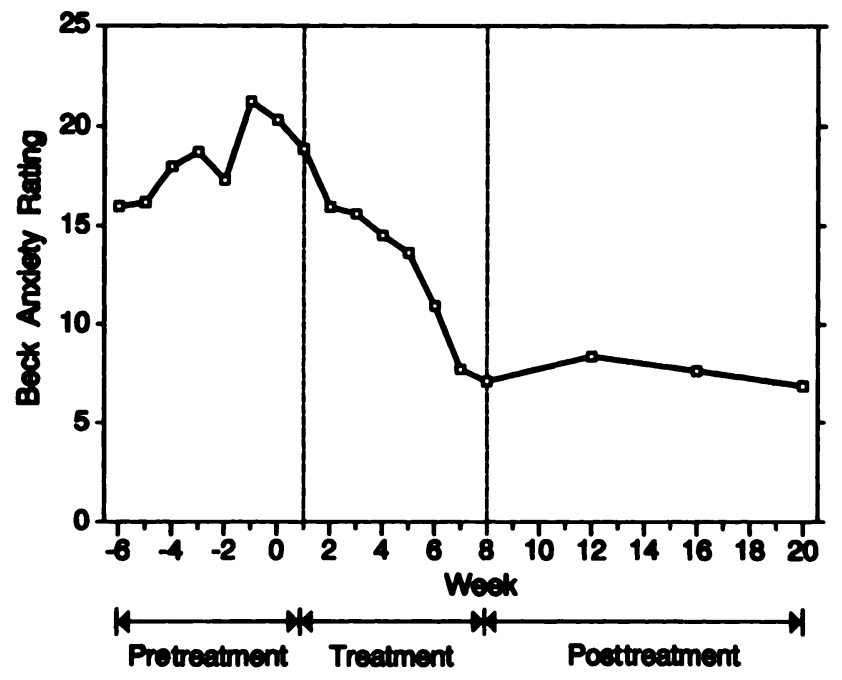

"The numbers of subjects for successive assessments were as follows: pretreatment, $4,5,7,11,12,16,21$; treatment, 20, 22, 22, 21, 22 , 21, 21, 19; posttreatment, 21, 19, 21.

$(S D=8.30)$ and the mean posttreatment Hamilton panic score was $8.36(S D=12.68)(t=4.07, d f=10, p<0.005)$. The mean number of panic attacks registered on the Hamilton anxiety scale and their severity also declined significantly between pretreatment and posttreatment assessments in both groups, and these declines were maintained at 3-month follow-up (data not shown).

The pretreatment and posttreatment scores of the subjects receiving psychotropic medication did not differ significantly from those of the subjects not receiving medication during the study. Twelve patients were taking medication for anxiety before treatment and 13 after treatment; 11 were taking medication at follow-up. Two patients were able to decrease their use of medication between the posttreatment and follow-up assessments, and one increased the use of medication during the same period.

The pretreatment and posttreatment scores on the SCL-90-R and the Medical Symptom Checklist of the study participants in the stress reduction and relaxation program were compared with the scores on these scales of the nonstudy participants in the program who had met the initial screening criteria for the study to assess possible biasing effects from the more intense assessment protocol on the study participants. As can be seen in table 2, the mean pretreatment and posttreatment scores on the total Medical Symptom Checklist, the anxiety items of the Medical Symptom Checklist, the general severity index of the SCL-90-R, and the anxiety subscale of the SCL-90-R for the 22 subjects in the study were comparable to those of the nonstudy participants in the program. The two groups showed statistically significant and equivalent symptom reduction on these measures over the intervention period.
FIGURE 2. Mean Beck Depression Imventory Ratines Before, Durine, and After Treatment of Patients in a Meditation-Based Stress Reduction Proegram

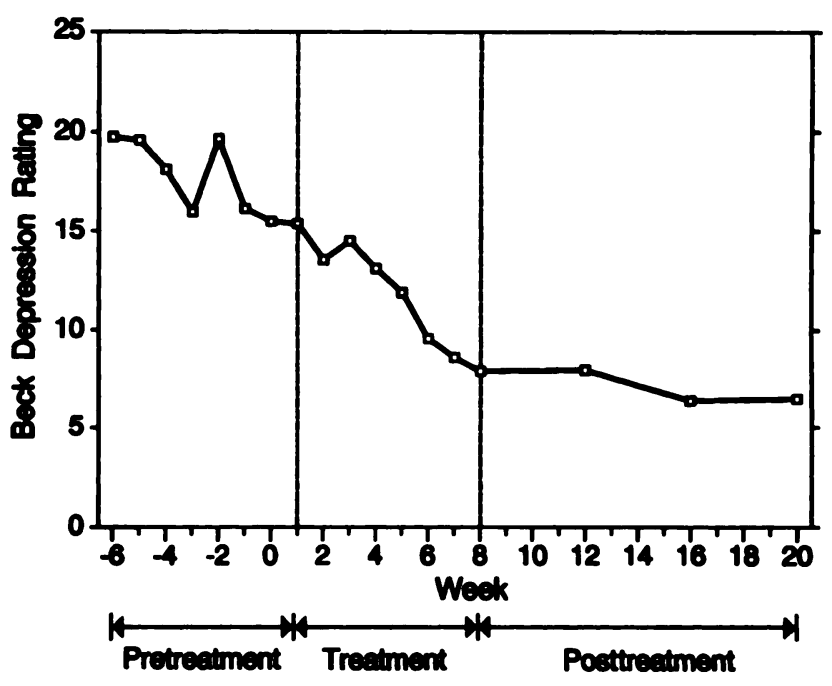

-The numbers of subjects for successive assessments were as follows: pretreatment, $4,5,7,11,12,17,21$; treatment, $20,22,21,21,22$, 21, 22, 19; posttreatment, 21, 20, 21.

When changes from before to after treatment in anxiety scores and in the number of panic attacks were examined on an individual basis, 20 of the 22 study subjects showed marked improvement (only one patient still had a score over 20 on the Beck Anxiety Inventory after treatment), making it difficult to examine predictors of differential outcome. Consistent with this uniformity of response, no demographic or baseline variables were significantly predictive of outcome. Expectancy ratings also failed to serve as a meaningful predictor of outcome. Self-reported amount of practice (compliance) was also not significantly correlated with any outcome measure. Furthermore, there were no statistically significant differences in outcome between patients with generalized anxiety disorder and those with panic disorder with or without agoraphobia, nor was the diagnosis of major depressive episode associated with outcome.

Adherence to the meditation practices taught in the stress reduction and relaxation program was assessed at 3-month follow-up. In response to the question "Have you been keeping up practice of the stress reduction techniques?" $91 \%$ (20 of the 22 subjects) replied in the affirmative, with a relatively homogeneous distribution between single meditation techniques and combinations of methods. Eighty-four percent $(\mathrm{N}=16)$ of the 19 who responded to this item were practicing formally three or more times per week; $42 \%(\mathrm{~N}=8)$ were practicing for 45 minutes or more at a time, $16 \%(\mathrm{~N}=3)$ for between 30 and 45 minutes at a time, and $37 \%(\mathrm{~N}=$ 7) for between 15 and 30 minutes at a time. Twenty-one subjects reported continued use of mindfulness of breathing (an informal mindfulness practice) in their daily lives, with $77 \%(\mathrm{~N}=17)$ using it "often" and $18 \%$ $(\mathrm{N}=4)$ using it "sometimes." 


\section{DISCUSSION}

The rate of completion of the program among the study subjects was high (22 of 24 subjects, or $92 \%$ ), consistent with previous studies of the stress reduction and relaxation program (18). Twenty of 22 subjects showed marked improvement in both anxiety and depression after the intervention. This improvement was maintained at 3-month follow-up. Improvement was observed both in patients' self-ratings (Beck anxiety and depression scales) and in interviewers' ratings (Hamilton anxiety and depression scales).

Of considerable importance is the statistically significant reduction from pretreatment assessment to posttreatment assessment in the number of subjects reporting one or more panic attacks, an improvement that was maintained at follow-up. There was a statistically nonsignificant tendency for the Hamilton panic scores to decrease between pretreatment and follow-up, suggesting that for the subjects who continued to have panic attacks during and after the intervention, the severity of those attacks declined.

Fear survey and mobility inventory scores also improved significantly, but these changes began during the pretreatment period, suggesting both an effect of the general expectancy of participation and an effect of the exposure to a therapeutic milieu during the evaluation visits.

The uniformly positive response to treatment among the subjects in this small study precluded a successful analysis of predictors of outcome. Compliance was also uniformly reported as moderate to high, indicative of the subjects' positive response to the intervention approach and the successful adoption of a range of new behaviors, including both formal and informal meditation practice.

A major strength of this study was the careful diagnostic assessment procedure we used to obtain DSMIII-R diagnoses. Previous studies investigated the use of meditation with normal populations or populations identified by using only nondiagnostic criteria. Such studies may therefore have included patients who would not have met the DSM-III-R criteria for generalized anxiety disorder or panic disorders. The results of this study, which focused specifically on patients with generalized anxiety disorder or panic with or without agoraphobia, suggest that mindfulness meditation used in a group format may be a useful treatment approach for these diagnostic groups.

It is also clear that the improvements in panic and anxiety which we observed cannot be attributed solely to participation in the study itself. This is established by the comparison showing that the subjects who participated in the study and the patients in the stress reduction program who met the screening criteria but were not subjected to the intensive research protocol achieved similar reductions in anxiety scores on the SCL-90-R and the Medical Symptom Checklist. This comparison also demonstrates that the results obtained with the study subjects are very likely generalizable to
TABLE 2. Pretreatment and Posttreatment Scores of Patients With Anxiety Disorders in a Study of a Meditation-Based Stress Reduction Program Compared With Scores of Nonstudy Participants in the Program Who Met Initial Screening Criteria for the Study"

\begin{tabular}{|c|c|c|c|c|c|c|}
\hline \multirow[b]{2}{*}{ Measure } & \multicolumn{3}{|c|}{$\begin{array}{c}\text { Study } \\
\text { Participants in } \\
\text { Program }\end{array}$} & \multicolumn{3}{|c|}{$\begin{array}{l}\text { Nonstudy } \\
\text { Participants in } \\
\text { Program }\end{array}$} \\
\hline & $\mathbf{N}$ & Mean & SD & $\mathbf{N}$ & Mean & SD \\
\hline \multicolumn{7}{|l|}{ Medical Symptom } \\
\hline $\begin{array}{l}\text { Checklist } \\
\text { Total score }\end{array}$ & 21 & & & 99 & & \\
\hline $\begin{array}{l}\text { Pretreatment } \\
\text { Posttreatment }\end{array}$ & & $\begin{array}{l}32.05 \\
23.10\end{array}$ & $\begin{array}{l}13.33 \\
17.75\end{array}$ & & $\begin{array}{l}30.97 \\
19.59\end{array}$ & $\begin{array}{l}11.55 \\
12.66\end{array}$ \\
\hline \multicolumn{7}{|l|}{ Anxiety score ${ }^{b}$} \\
\hline Pretreatment & & 16.95 & 0.51 & & 15.96 & 4.67 \\
\hline Posttreatment & & 11.10 & 8.50 & & 10.17 & 5.53 \\
\hline $\begin{array}{l}\text { SCL-90-R } \\
\text { General severity } \\
\text { index score }\end{array}$ & 20 & & & 97 & & \\
\hline Pretreatment & & 1.08 & 0.73 & & 1.03 & 0.56 \\
\hline Posttreatment & & 0.60 & 0.54 & & 0.62 & 0.45 \\
\hline \multicolumn{7}{|c|}{ Anxiety subscale score } \\
\hline $\begin{array}{l}\text { Pretreatment } \\
\text { Posttreatment }\end{array}$ & & $\begin{array}{l}1.56 \\
0.69\end{array}$ & $\begin{array}{l}1.08 \\
0.68\end{array}$ & & $\begin{array}{l}1.27 \\
0.70\end{array}$ & $\begin{array}{l}0.79 \\
0.62\end{array}$ \\
\hline
\end{tabular}

${ }^{2}$ All within-group differences between pretreatment and posttreatment scores were significant $(p<0.05)$ in the two-tailed paired $t$ tests. None of the pretreatment scores differed significantly between study participants and nonstudy participants in the unpaired t tests, except on the anxiety subscale of the SCL-90-R, for which $\mathrm{p}=0.05$.

bean number of symptoms out of the 37 identified as characteristic of patients with anxiety disorders.

the much larger group of patients who met the initial criteria for the study.

The strong reductions in panic symptoms and frequency of panic attacks observed in this study are consistent with the cognitive model of panic (30) and with clinical outcomes from studies of panic disorder in which well-established cognitive (31) and cognitive-behavioral (32) intervention approaches were used. The meditative approach used in the stress reduction and relaxation program shares some attributes with both cognitive and behavioral therapeutic approaches used to treat anxiety and panic. It also differs structurally and theoretically from them in a number of noteworthy respects, as has been noted in a different context by others $(33,34)$.

In particular, the meditative, cognitive, and cognitivebehavioral approaches share an emphasis on noting sensations and thoughts without viewing them as catastrophic and the use of stress-inducing situations as cues to engage in new behaviors. They also have in common the use of homework assignments to reinforce what was learned in the group sessions. However, the stress reduction and relaxation program differs from cognitive and cognitive-behavioral models in the following important respects.

1. Emphasis is not placed on distinguishing thoughts as positive, negative, or faulty, as in cognitive therapy. Rather, the emphasis is on identifying thoughts as "just" thoughts and acknowledging the potential inaccuracy and limits of all thought, not just thoughts that produce anxiety. This attitude is cultivated in the peri- 
ods of formal meditation practice, as well as in informal mindfulness practiced in the course of daily activity.

2. The formal meditation is taught as a daily discipline to be practiced regularly, independent of one's state of anxiety. The emphasis is on meditation as a way of being, as a way of living one's life, and as a way to develop alternative "generic" strategies for coping with stress and pain, rather than as a technique for coping with a specific problem such as panic.

3. The intervention takes place in a nonpsychiatric medical setting with a heterogeneous group of patients who have a wide range of medical and psychological problems. This is a significant departure from the model of cognitive-behavioral therapy, which is typically provided to individuals or groups of patients with a single disorder. Moreover, the focus of the intervention is on the meditation practice itself rather than on a specific disorder or diagnosis or constellation of symptoms.

4. Unlike Barlow's cognitive-behavioral approach, in which subjects are systematically exposed through specific induction exercises to feared internal sensations associated with panic, such as cardiovascular symptoms, hyperventilation, dizziness, and chest muscle tightness (35), there is no attempt at systematic desensitization through the induction of symptoms of any kind during the stress reduction and relaxation program. Although stressful or anxiety-related symptoms are not intentionally evoked, when these experiences arise, either during formal meditation or in the course of daily living, patients are encouraged to see them as opportunities to engage in mindful coping strategies as an alternative to more habitual patterns of emotional reactivity. In this respect, the program utilizes a cognitive restructuring that overlaps with other cognitive and cognitive-behavioral approaches.

5. The observational skills cultivated through mindfulness training differ substantially from those developed by behavioral monitoring techniques. Participants in the program are trained initially to develop concentration (one-pointed attention) through systematic and continued focusing on a restricted field of observation such as breathing or proprioception. Concentration lends stability to one's capacity to observe fearful thoughts and feelings in a nonreactive way. Coupled with mindfulness, concentration gives rise to a nondiscursive, nonanalytical, direct experiencing of the object of attention. This is in contrast to the external data gathering involved in behavioral analysis of antecedents and consequences.

Patients who are able to identify anxious thoughts as thoughts, rather than as "reality," report that this alone helps reduce their anxiety and increases their ability to encounter anxiety-producing situations more effectively. The insight that one is not one's thoughts means that one has a potential range of responses to a given thought if one is able to identify it as such. This increased range of options is associated with a feeling of control. It might be hypothesized that this is a feature of a cognitive pathway explaining the clinical observations in this study.
With regard to treatment validation, it should be noted that the duration of meditation practice in the weekly classes becomes incrementally longer over the course of the intervention. By the eighth week, most patients sit in silence in class, with little overt movement for periods of up to $\mathbf{4 5}$ minutes. This is a profound behavior change for most patients with panic disorder or anxiety. Such extended periods of stillness serve as an observable behavioral indicator of an individual's increasing ability to concentrate and achieve a degree of calmness over the intervention period. The all-day silent intensive session in the sixth week of the program, involving over 150 patients in one large room, is also an empirical indicator of the development of new behavior. It can be a substantial challenge for patients with panic disorder to sit still for long periods of time, attempting to observe anxious thoughts and impulses as they arise and working with them mindfully rather than succumbing to impulses of reactivity and panic.

A salient limitation of this pilot study is that it did not have a randomly selected comparison group. It also lacked a control for concomitant treatment. However, the group of patients receiving medication showed symptom reduction equivalent to that of the group not receiving any medication, a finding which suggests that the mindfulness approach may be equally useful for patients who receive pharmacotherapy and those who do not. As in treatment studies comparing imipramine and alprazolam $(36,37)$ and a study of nonpharmacological therapies (6), patients with generalized anxiety disorder and patients with panic disorder responded equally well to the program intervention. However, the number of patients in these two diagnostic categories was small, and a larger, randomized study would be required to determine whether the stress reduction and relaxation program is equally effective in each case or in the case of patients who are receiving pharmacotherapy compared with those who are not. A larger randomized study would also be valuable for comparing the mindfulness-based intervention with other cognitive and cognitive-behavioral therapies.

We observed parallel changes in anxiety and depression scale scores after the meditation program that were similar to those noted by Borkovec et al. (5). However, the presence of comorbid depression in eight subjects in our study was not associated with a statistically significant difference in outcome, as was previously reported (38). This result could mean that the intervention was helpful in alleviating depressive as well as anxiety symptoms. Alternatively, it could have been an artifact of the small size of the study group.

In summary, this pilot study of the efficacy of training in mindfulness meditation in the context of a group stress reduction clinic for medical outpatients showed statistically and clinically significant reductions in symptoms of anxiety and depression in patients with the three core anxiety disorders (generalized anxiety disorder, panic disorder, and panic disorder with agoraphobia) diagnosed according to the DSM-III-R criteria. These changes appeared to be independent of par- 
ticipation in the research protocol and were maintained at 3-month follow-up.

\section{ADDENDUM}

A recently completed long-term follow-up conducted with 18 of the 22 subjects in this study found that after 3 years, the 3-month follow-up levels of anxiety and depression reported here had been maintained.

\section{REFERENCES}

1. Shapiro DH Jr: Meditation: Self-Regulation Strategy and Altered States of Consciousness. New York, Aldine, 1980

2. Shapiro DH Jr: Overview: clinical and physiological comparison of meditation with other self-control strategies. Am J Psychiatry 1982; 139:267-274

3. Shapiro DH Jr, Walsh RN (eds): Meditation: Classic and Contemporary Perspectives. New York, Aldine, 1984

4. Garfield SL, Bergin AE: Handbook of Psychotherapy and Behavior Change: An Empirical Analysis. New York, John Wiley \& Sons, 1978

5. Borkovec TD, Mathews AM, Chambers A, Ebrahimi S, Lytle R, Nelson R: The effects of relaxation training with cognitive or nondirective therapy and the role of relaxation-induced anxiety in the treatment of generalized anxiety. J Consult Clin Psychol 1987; 55:883-888

6. Borkovec TD, Matthews AM: Treatment of nonphobic anxiety disorders: a comparison of nondirective, cognitive, and coping desensitization therapy. J Consult Clin Psychol 1988; 56:877884

7. Delmonte MM: Meditation and anxiety reduction: a literature review. Clin Psychol Rev 1985; 5:91-102

8. Talbott JA, Hales RE, Yudofsky SC (eds): The American Psychiatric Press Textbook of Psychiatry. Washington, DC, American Psychiatric Press, 1988, p 458

9. Raskin M, Bali, LR, Peeke HV: Muscle biofeedback and transcendental meditation. Arch Gen Psychiatry 1980; 37:93-97

10. Benson H, Frankel FH, Apfel R, Daniels MD, Schniewind HE Nemiah JC, Sifneos PE, Crassweller KD, Greenwood MM, Kotch JB, Arns PA, Rosner B: Treatment of anxiety: a comparison of the usefulness of self-hypnosis and a meditational relaxation technique: an overview. Psychother Psychosom 1978; 30: 229-242

11. Girodo M: Yoga meditation and flooding in the treatment of anxiety neurosis. J Behav Ther Exp Psychiatry 1974; 5:157-160

12. Kutz I, Leserman J, Dorrington C, Morrison CH, Borysenko JZ, Benson H: Meditation as an adjunct to psychotherapy: an outcome study. Psychother Psychosom 1985; 43:209-218

13. Thera N: The Heart of Buddhist Meditation. New York, Samuel Weiser, 1962, p 4

14. Kabat-Zinn J: Full Catastrophe Living. New York, Delacorte, 1990

15. Goleman DJ, Schwartz GE: Meditation as an intervention in stress reactivity. J Consult Clin Psychol 1976; 44:456-466

16. Goleman D: The Meditative Mind. Los Angeles, Tarcher, 1988

17. Kabat-Zinn J: An outpatient program in behavioral medicine for chronic pain patients based on the practice of mindfulness medi- tation: theoretical considerations and preliminary results. Gen Hosp Psychiatry 1982; 4:33-42

18. Kabat-Zinn J, Chapman-Waldrop A: Compliance with an outpatient stress reduction program: rates and predictors of program completion. J Behav Med 1988; 11:333-352

19. Kabat-Zinn J, Lipworth L, Burney R: The clinical use of mindfulness meditation for the self-regulation of chronic pain. J Behav Med 1985; 8:163-190

20. Kabat-Zinn J, Lipworth L, Burney R, Sellers W: Four-year follow-up of a meditation-based program for the self-regulation of chronic pain: treatment outcomes and compliance. Clin J Pain 1986; 2:159-173

21. Derogatis LR: SCL-90-R Manual II. Towson, Md, Clinical Psychometric Research, 1983

22. Spitzer RL, Williams JBW, Gibbon M: Structured Clinical Interview for DSM-III-R (SCID). New York, New York State Psychiatric Institute, Biometrics Research, 1987

23. Beck AT, Ward CH, Mendelson M, Mock J, Erbaugh J: An inventory for measuring depression. Arch Gen Psychiatry 1961; 4:561-571

24. Hamilton $\mathrm{M}$ : The assessment of anxiety states by rating. $\mathrm{Br} \mathrm{J}$ Med Psychol 1959; 32:50-55

25. DiNardo PA, Barlow DH: Anxiety Disorders Interview ScheduleRevised (ADIS-R). Albany, NY, Graywind Publications, 1988

26. Williams JBW: A structured interview guide for the Hamilton Depression Rating Scale. Arch Gen Psychiatry 1988; 45:742747

27. Arrindell WA, van der Ende J: Further evidence for cross-sample invariance of phobic factors: psychiatric inpatient ratings on the Fear Survey Schedule-III. Behav Res Ther 1986; 24:289-297

28. Chambless DL, Caputo CG, Jasin SE, Gracely EJ, Williams C: The Mobility Inventory for Agoraphobia. Behav Res Ther 1985; 23:35-44

29. Cohen J, Cohen T: Applied Multiple Regression/Correlation: Analysis for the Behavioral Sciences, 2nd ed. Hillsdale, NJ, Lawrence Erlbaum Associates, 1990, pp 413-423

30. Clark DM: A cognitive approach to panic. Behav Res Ther 1986; 24:461-470

31. Clark DM, Salkovskis PM, Chalkley AJ: Respiratory control as a treatment for panic attacks. J Behav Ther Exp Psychiatry 1985; $16: 23-30$

32. Barlow DH, Craske MG, Cerny JA, Klosko JS: Behavioral treatment of panic disorder. Behavior Therapy 1989; 20:261-282

33. Shapiro DH Jr, Zifferblatt SM: Zen meditation and behavior self-control: similarities, differences, and clinical applications. Am Psychol 1976; 31:519-532

34. Walsh R: The consciousness disciplines and the behavioral sciences: questions of comparison and assessment. Am J Psychiatry $1980 ; 137: 663-673$

35. Barlow DH: Long-term outcome for patients with panic disorder treated with cognitive-behavioral therapy. J Clin Psychiatry 1990; 51(suppl A):17-23

36. Charney DS, Woods SW, Goodman WK, Rifkin B, Kinch M, Aiken B, Quadrino LM, Heninger GR: Drug treatment of panic disorder: the comparative efficacy of imipramine, alprazolam, and trazodone. J Clin Psychiatry 1986; 47:580-586

37. Gershon S, Eison AS: The ideal anxiolytic. Psychiatr Annals 1987; 17:156-170

38. VanValkenburg C, Akiskal HS, Puzantian V, Rosenthal T: Anxious depressions: clinical, family history, and naturalistic outcome: comparisons with panic and major depressive disorders. J Affective Disord 1984; 6:67-82 